\title{
Patterns in woody vegetation structure across African savannas
}

\author{
Christoffer R. Axelsson ${ }^{1}$ and Niall P. Hanan ${ }^{2}$ \\ ${ }^{1}$ Geospatial Sciences Center of Excellence, South Dakota State University, Brookings, SD, USA \\ ${ }^{2}$ Plant and Environmental Sciences, New Mexico State University, Las Cruces, NM, USA
}

Correspondence to: Christoffer R. Axelsson (christoffe@ hotmail.com)

Received: 10 January 2017 - Discussion started: 18 January 2017

Revised: 17 May 2017 - Accepted: 2 June 2017 - Published: 10 July 2017

\begin{abstract}
Vegetation structure in water-limited systems is to a large degree controlled by ecohydrological processes, including mean annual precipitation (MAP) modulated by the characteristics of precipitation and geomorphology that collectively determine how rainfall is distributed vertically into soils or horizontally in the landscape. We anticipate that woody canopy cover, crown density, crown size, and the level of spatial aggregation among woody plants in the landscape will vary across environmental gradients. A high level of woody plant aggregation is most distinct in periodic vegetation patterns (PVPs), which emerge as a result of ecohydrological processes such as runoff generation and increased infiltration close to plants. Similar, albeit weaker, forces may influence the spatial distribution of woody plants elsewhere in savannas. Exploring these trends can extend our knowledge of how semi-arid vegetation structure is constrained by rainfall regime, soil type, topography, and disturbance processes such as fire. Using high-spatial-resolution imagery, a flexible classification framework, and a crown delineation method, we extracted woody vegetation properties from 876 sites spread over African savannas. At each site, we estimated woody cover, mean crown size, crown density, and the degree of aggregation among woody plants. This enabled us to elucidate the effects of rainfall regimes (MAP and seasonality), soil texture, slope, and fire frequency on woody vegetation properties. We found that previously documented increases in woody cover with rainfall is more consistently a result of increasing crown size than increasing density of woody plants. Along a gradient of mean annual precipitation from the driest $\left(<200 \mathrm{~mm} \mathrm{yr}^{-1}\right)$ to the wettest $(1200$ $1400 \mathrm{~mm} \mathrm{yr}^{-1}$ ) end, mean estimates of crown size, crown density, and woody cover increased by 233,73 , and $491 \%$ respectively. We also found a unimodal relationship between mean crown size and sand content suggesting that maximal
\end{abstract}

savanna tree sizes do not occur in either coarse sands or heavy clays. When examining the occurrence of PVPs, we found that the same factors that contribute to the formation of PVPs also correlate with higher levels of woody plant aggregation elsewhere in savannas and that rainfall seasonality plays a key role for the underlying processes.

\section{Introduction}

African savannas are complex tree-grass systems controlled by combinations of climate, soil, and disturbance processes such as fire and herbivory (Sankaran et al., 2008). In dry savannas, water availability determines the establishment, growth and survival of plants and competitive plant traits are often of a water-saving nature (Chesson et al., 2004; Pillay and Ward, 2014). Abiotic environmental factors, such as the rainfall regime, soil type, and topography, impact ecohydrological processes by controlling infiltration rates, runoff generation, and available water capacity, which in turn impact the growth and survival of woody plants in the landscape (Ludwig et al., 2005). Climate, both rainfall patterns and temperatures, could change in many parts of Africa (Gan et al., 2016), and the effect on vegetation will depend on how those pressures interact with other abiotic and biotic factors. In addition to ecohydrological factors, savannas are heavily influenced by the frequency and intensity of fires (Bond, 2008), as well as herbivore regimes (Sankaran et al., 2008), which often combine to suppress woody cover to levels well below its climatic potential (Sankaran et al., 2005). A thorough understanding of the underlying processes that influence savanna vegetation structure is key to assessing the future resilience and productivity of these ecosystems. 
Across environmental gradients we expect to see variation in woody vegetation properties, including individuallevel characteristics (mean crown size) and population-level characteristics (crown density, woody cover, and the spatial distribution of plants in the landscape). Woody cover is fundamentally a function of crown sizes and crown density and by studying these components individually, it is possible to attain important insight into the function of ecosystems and what ecosystem services they provide. Two landscapes with similar woody cover but different sizes of individual trees will sequester different amounts of carbon (Shackleton and Scholes, 2011), harbor different fauna (Riginos and Grace, 2008), and differ in biogeochemical dynamics (Veldhuis et al., 2016a). The level of spatial aggregation among woody plants can help us understand facilitative and competitive processes determining survival of seedlings and saplings. Woody plants increase water infiltration and local accumulation of soil and nutrient resources, as well as altering sub-canopy microclimates (Barbier et al., 2014; Dohn et al., 2017; Gómez-Aparicio et al., 2008). These short-range facilitative effects usually operate at spatial scales of a few meters but may increase the degree of aggregation among woody plants at larger scales (Scanlon et al., 2007; Xu et al., 2015). Overland flows of water can be especially effective at redistributing resources over longer distances, in some conditions leading to the emergence of periodic vegetation patterns (PVPs; Rietkerk and van de Koppel, 2008; Valentin et al., 1999). Contrasting infiltration rates between bare and vegetated patches lead to redistribution of water and soil resources, which reinforces an organized pattern. While soil texture type has been weakly associated with the occurrence of PVPs (Deblauwe et al., 2008), the impervious conditions of the bare patches are generally caused by shallow soil depths, hardpans, or soil crusts (McDonald et al., 2009). On flat ground, PVPs take the form of spotted, labyrinthine, or gapped patterns depending on soil water availability. On a gentle slope, they develop into vegetated bands that run parallel to contour lines (Valentin et al., 1999). While PVPs have been studied extensively, their formative processes are seldom linked to ecohydrological processes in other types of savanna landscapes.

To analyze how woody cover, crown size, crown density and the spatial pattern of trees vary with environmental gradients, we need to map the landscape at the level of individual trees. Satellite-based high-spatial-resolution (HSR; $<4 \mathrm{~m}$ ) sensors have the necessary degree of detail for this task. Papers delineating individual trees from HSR in African savannas have shown promising results (Karlson et al., 2014; Rasmussen et al., 2011), but these studies are generally restricted to small geographical areas. In this paper we present an analysis of woody properties sampled across the diverse waterlimited savannas of Africa using a combination of WorldView, Quickbird, and GeoEye satellite data $(\leq 0.61 \mathrm{~m}$ resolution) from 876 sites. The woody components of the sites were classified and delineated into individual tree crowns, from which we derived estimates of mean crown size, crown density, woody cover, and the degree of aggregation among woody plants. We then analyzed how these woody vegetation properties vary with rainfall regime (MAP and seasonality), soil texture, slope, and fire frequency using a boosted regression tree (BRT) approach. The dataset contains sites from several areas with PVPs and we also investigated the environmental factors associated with the occurrence of highly organized periodic patterns.

\section{Data and methodology}

Our methodological approach included a flexible classification approach based on unsupervised classification, tree crown delineation, and boosted regression tree analysis (Fig. 1).

\subsection{Satellite data and sampling strategy}

We used data from WorldView-2, WorldView-3, GeoEye-1, and Quickbird-2 satellites, with varying ground resolutions $(\leq 0.61 \mathrm{~m}$ for panchromatic data and $\leq 2.44 \mathrm{~m}$ for the multispectral bands). The sampling frame for the analysis was sub-Saharan African savannas with a minimum of anthropogenic disturbances. When acquiring data, we adopted a sampling strategy with imagery distributed across Africa in rangelands as defined by the anthropogenic biomes product (Ellis and Ramankutty, 2008) (Fig. 2), which helped us identify and avoid areas with high anthropogenic impact. Focus was on selecting recent images (2011-2016) when trees were in full leaf (generally in the mid- to late growing season) and avoid areas of high human population density. The selection process was also influenced by a second study on change detection where we needed overlapping imagery from two points in time. We excluded images with view angles $>25^{\circ}$ or cloud cover $>20 \%$. Following these criteria, we acquired imagery in 48 regions, within which we sampled $240 \times 240 \mathrm{~m}$ sites for use in the analysis. Within-image site selection followed a systematic sampling approach and was guided by a $0.04^{\circ}$ longitude/latitude grid which served as a base for site locations. In some cases, however, the location of sites was adjusted to avoid areas where vegetation structure was clearly influenced by topography (rocky outcrops, streams and gullies), or anthropogenic activity (settlements, roads, active or fallow agriculture). Sample locations influenced by topographic or anthropogenic effects were either moved to a nearby location or eliminated from the analysis. During the later classification process, we found that some sites could not be classified reliably due to either low image quality or a lack of contrast between trees and the herbaceous background. These sites were also eliminated. In the end, we ended up with a total of 876 sites (Fig. 2). 


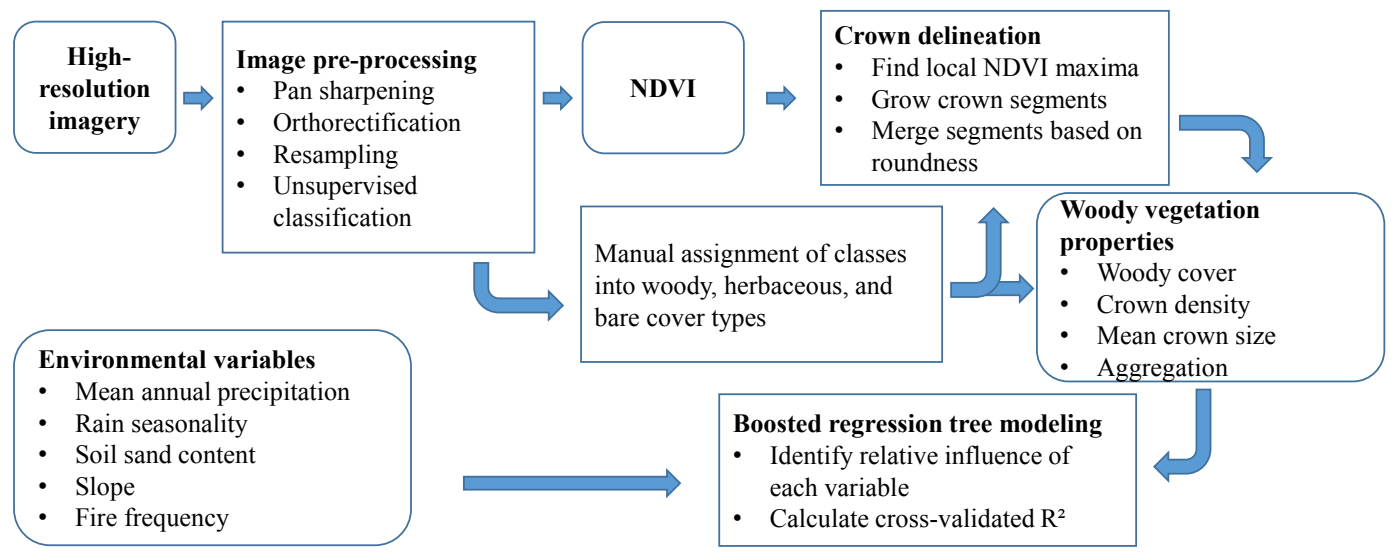

Figure 1. Methodological workflow showing datasets (rounded boxes) and methods (square boxes) used to estimate woody vegetation structure and analyze relationships with environmental variables.

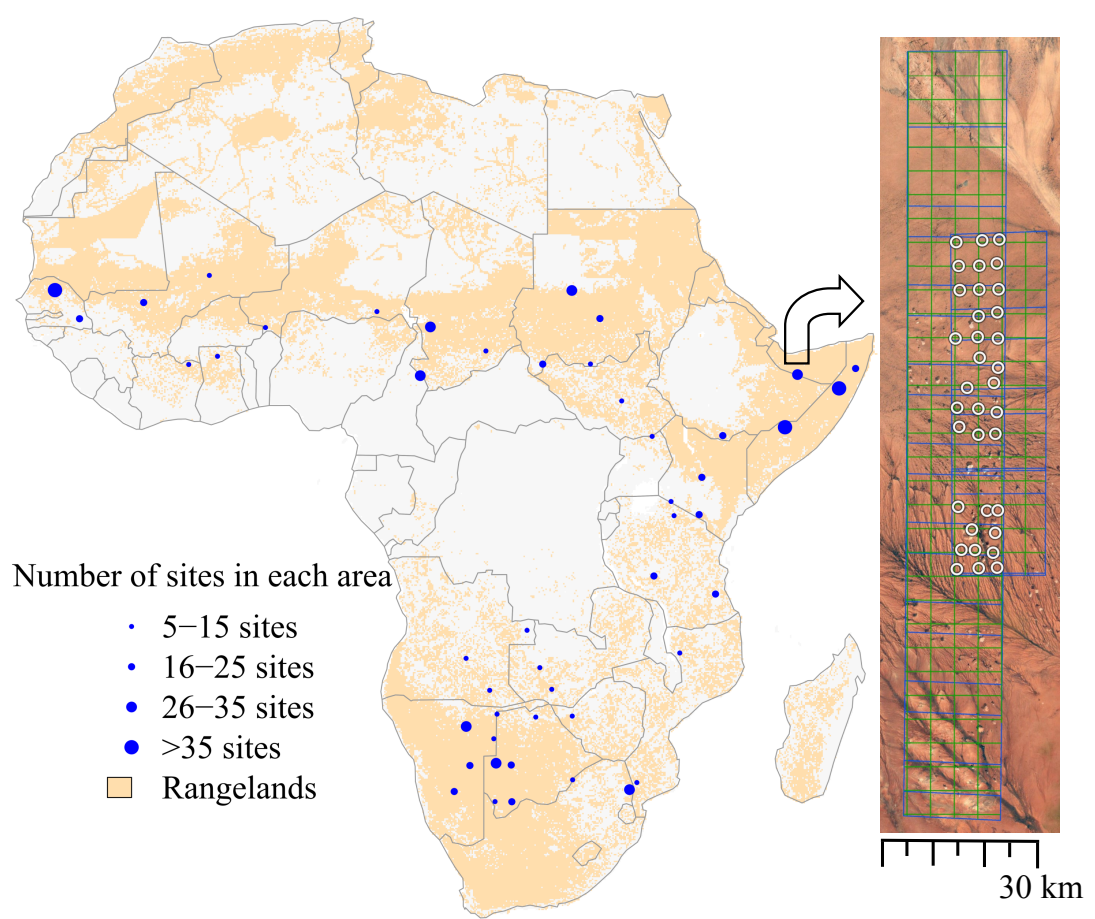

Figure 2. Location of the 48 study areas, containing 876 study sites, spread out over African rangelands. The rangeland areas are from the anthropogenic biomes product (Ellis and Ramankutty, 2008), and symbol size for study areas is proportional to the number of study sites in each. The map to the right shows a study area on the border between Somalia and Ethiopia and exemplifies the sampling strategy for study sites (white rings). The placement of sites was guided by a $0.04^{\circ}$ longitude-latitude grid (green lines) in areas with overlapping older and newer satellite imagery (blue lines).

\subsection{Preprocessing and classification of satellite data}

Once the locations of sites were established, each site was preprocessed using IDL scripts in ENVI 5.2. This included Gram-Schmidt pan sharpening of the blue, green, red, and infrared bands, and orthorectification using embedded rapid positioning coordinate (RPC) information and an SRTM v2 DEM (Farr et al., 2007). The orthorectified images were re- sampled using a nearest-neighbor method to a standard $0.6 \mathrm{~m}$ ground resolution creating a $400 \times 400$ pixel $(240 \times 240 \mathrm{~m})$ image centered over each site. We then ran unsupervised ISODATA classification on the pan-sharpened images to create 18 spectrally different classes, which were smoothed using a kernel size of 3 pixels. Following preprocessing, the 18 spectrally distinct classes were manually assigned to woody, herbaceous, and bare cover classes using custom- 
built software in R. The software includes several tools to facilitate accurate and efficient classifications, including a tool to split a class into two spectrally different classes if it appears to contain more than one land cover type, and a tool to remove minor inconsistencies such as a single herbaceous pixel in the middle of a tree crown.

\subsection{Crown delineation}

After the $240 \times 240 \mathrm{~m}$ image constituting each study site was classified into woody, herbaceous, and bare soil components, a crown delineation process was run to aggregate woody pixels into individual tree crown polygons. The method uses the classified woody layer (as the "forest mask") together with normalized difference vegetation index (NDVI) from the pan-sharpened imagery and is based on the assumption that woody plants have higher NDVI at the center of the crown, where branches and leaves are dense, and declining NDVI towards the outer edges of the crown where branch and leaf density tend to be lower. The first step in the delineation process is to identify local maxima in NDVI. If the center pixel in the $3 \times 3$ pixel neighborhood is a maximum, it is given a unique segment ID and serves as a seed for a crown segment. The second step involves iterative growth of segments in all directions, but only to woody pixels with lower NDVI than the neighboring segment pixel. In the third step, neighboring segments are merged if the resulting crown is rounder than both of the two neighboring segments. Since the merging criteria can be fulfilled for several segment neighbors, a segment is only merged once in each iteration and the merging order is based on the roundness of the resulting segments. Here, roundness is calculated as the area of the segment divided by the area of a minimum bounding circle. Round segments thereby get values close to one, while more complex segment forms have lower roundness. This step is re-iterated until rounder segments cannot be formed (Fig. 3). We also added a maximum crown size limit so that segments are not merged if the resulting crown is larger than the area of a circle with diameter $40 \mathrm{~m}$, as trees larger than this size are very rare throughout the sampling frame. The method was implemented in $\mathrm{C}$ code and has several traits in common with previous delineation methods (e.g., Bunting and Lucas, 2006; Culvenor, 2002; Karlson et al., 2014; Pouliot and King, 2005) which generally were developed and tuned for a specific landscape type. The method by Bunting and Lucas (2006) is perhaps the most similar since it also identifies segment seeds using local maxima of a vegetation index, iteratively expands to neighboring pixels, and has iterations of segment merging. That method was developed using the eCognition software and has some additional steps not included in our method, such as post-splitting of segments and the initial generation of a forest mask. In our methodology, the forest mask (woody areas) was already established using the semi-automatic approach described above.

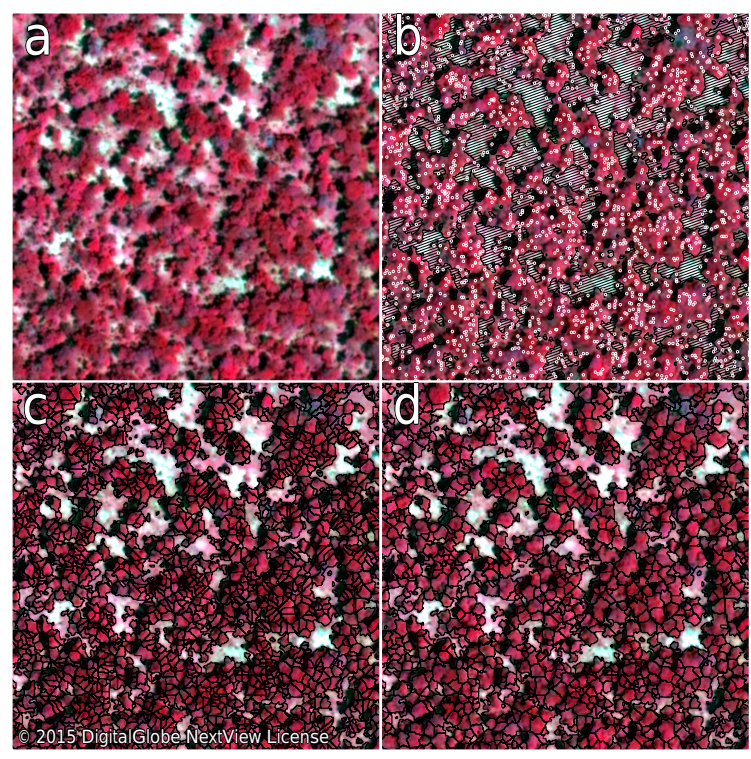

Figure 3. Crown delineation steps for a woodland site in Zambia. (a) Pan-sharpened false-color image, (b) local NDVI maxima as white points and the non-woody areas shown as striped polygons, (c) crown segments before merging, and (d) the final crown polygons following crown merging.

The delineated crowns played an important role in this analysis because they were used for calculating crown density, crown sizes, and woody plant aggregation. Our analysis of the derived woody properties did not focus on absolute numbers but on how they vary across environmental gradients under the assumption that errors were propagated consistently over space. A visual inspection of all sites indicated that the crown delineation consistently produced crown layers that looked realistic when overlaying the imagery. We recognize, however, that it is extremely difficult to accurately delineate tree canopies in areas where crowns overlap. In some cases, a large tree crown may be falsely divided into small canopies or a cluster of shrubs may be grouped together into one crown (Rasmussen et al., 2011). It is important that the rate of falsely divided and falsely grouped crowns is balanced since excessive division of large trees into smaller leads to higher estimates of both crown density and aggregation. We evaluated the performance of the classification and delineation methodology using field data from sites in Kenya (Appendix A). This showed that crowns smaller than $\sim 2 \mathrm{~m}$ diameter were not reliably detected in the imagery. The validation analysis resulted in relatively strong agreement between estimated and field-measured woody properties with $R^{2}$ of 0.69 (mean crown size), 0.82 (crown density), and 0.77 (woody cover) when crowns smaller than $2 \mathrm{~m}$ diameter were removed from the field dataset. We did, however, find that particularly large and spread-out crowns were subdivided, leading to underestimation of crown sizes and overestimation of crown density. 


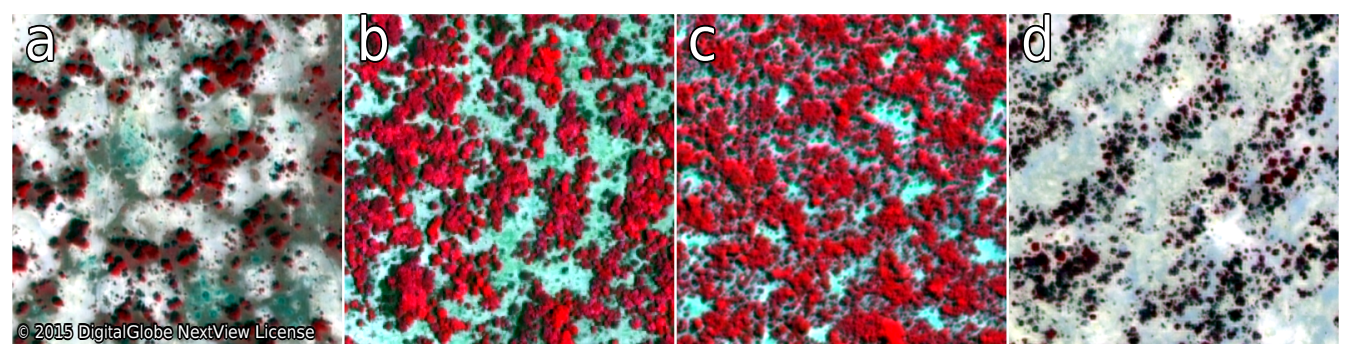

Figure 4. False-color imagery of periodic vegetation patterns identified among the sites: (a) spotted pattern in Senegal, (b) labyrinthine pattern in Mali, (c) gapped pattern in Niger, and (d) banded pattern in Somalia. Sites with PVPs were identified visually by the authors.

\subsection{Environmental variables}

The rainfall data were extracted from the Tropical Rainfall Measuring Mission (TRMM) 3B42 v7 product $\left(0.25^{\circ} \times 0.25^{\circ}\right)$ for the years $1998-2015$ (Huffman et al., 2007). In addition to mean annual precipitation (MAP), we used rainfall seasonality represented by the coefficient of variation of mean monthly rainfalls. For soil data we used the sand content in the top soil layer $(0-5 \mathrm{~cm})$ from the ISRIC/AfSIS $250 \mathrm{~m}$ soil property maps of Africa (Hengl et al., 2015). To represent topography we used slope (\%) derived from SRTM v2 ( 3 arcsec) elevation data (Farr et al., 2007). Fire frequency (fire events/year) was calculated using the MODIS MCD64A1 collection 5.1 burned area product (500 m resolution) for the years 2001-2015 (Giglio et al., 2009). To avoid registering fires identified in adjacent months as separate fires, we counted fire events in consecutive months as a single fire. The extraction of raster values was based on nearest neighbor to the center point of each site in all cases except the TRMM data, for which we used bilinear interpolation due to its coarse resolution.

\subsection{Statistical analysis of woody vegetation properties and the local environment}

We derived four statistical properties of woody vegetation from each image: mean crown size $\left(\mathrm{m}^{2}\right)$, density (crowns ha ${ }^{-1}$ ), woody cover $(\%)$, and spatial aggregation of woody plants. Aggregation was calculated from the center points of the crown polygons. We used Ripley's $K$ transformed to Besag's $L$ function to estimate aggregation at distances from 1 to $60 \mathrm{~m}$ (Besag, 1977; Ripley, 1977). Calculations were made using the spatstat $\mathrm{R}$ package with isotropic edge correction. The $L$ function was normalized by subtracting the distance so that 0 represents a random pattern and positive values indicate aggregation. For the analysis, we used the $L$ function at $20 \mathrm{~m}$ to represent aggregation as this distance is longer than the typical diameter of savanna trees and within length scales of facilitative tree-tree effects. When analyzing crown sizes and aggregation, we excluded all sites with a crown density of 10 crowns ha $^{-1}$ or less due to their low sample size for these metrics. We used boosted regression trees (BRTs, in the dismo $\mathrm{R}$ package) to relate woody properties to the environmental variables. Its advantages include the ability to model nonlinear relationships and to identify interactions between variables (Elith et al., 2008). When generating the BRTs, we used family $=$ Gaussian, tree complexity $=3$, learning rate $=0.01$, and bag fraction $=0.5$ as model parameters. $R^{2}$, calculated through 10 -fold crossvalidation, was used for evaluating the strength of the relationships.

The dataset includes several sites with PVPs, which often are treated as a special case because of their striking appearance (Fig. 4). It is of interest to examine the environmental conditions associated with the occurrence of PVPs as well as those associated with aggregated woody populations in savannas without PVPs. We therefore separated sites with periodic vegetation from the rest and generated an additional set of models. The category with periodic vegetation contained 149 sites situated in Somalia, Senegal, Chad, Mali, Niger, Namibia, and Sudan. The identification was based on visual inspection, and all sites with traits of periodic patterning (spotted, labyrinthine, gapped, or banded) were put in the PVP category. We created one model for predicting aggregation among all sites, one for predicting aggregation among sites with no PVPs, and a third for predicting the occurrence PVPs. In the latter model, all PVP sites were given the value 1 and the rest 0 , and the BRT family parameter was set to "bernoulli”, appropriate for binomially distributed data.

\section{Results}

We started by calculating frequency distributions of the four woody properties divided into three rainfall categories (Fig. 5). The more arid savannas $\left(<400 \mathrm{~mm} \mathrm{yr}^{-1}\right)$ typically featured smaller crown sizes, lower crown density and woody cover, and higher levels of aggregation than sites in the wetter categories.

\subsection{Mean crown size, density, and woody cover}

Boxplots with woody properties divided into MAP bins (Fig. 6) show that woody cover and crown sizes increased more sharply with increasing rainfall than crown densities. 

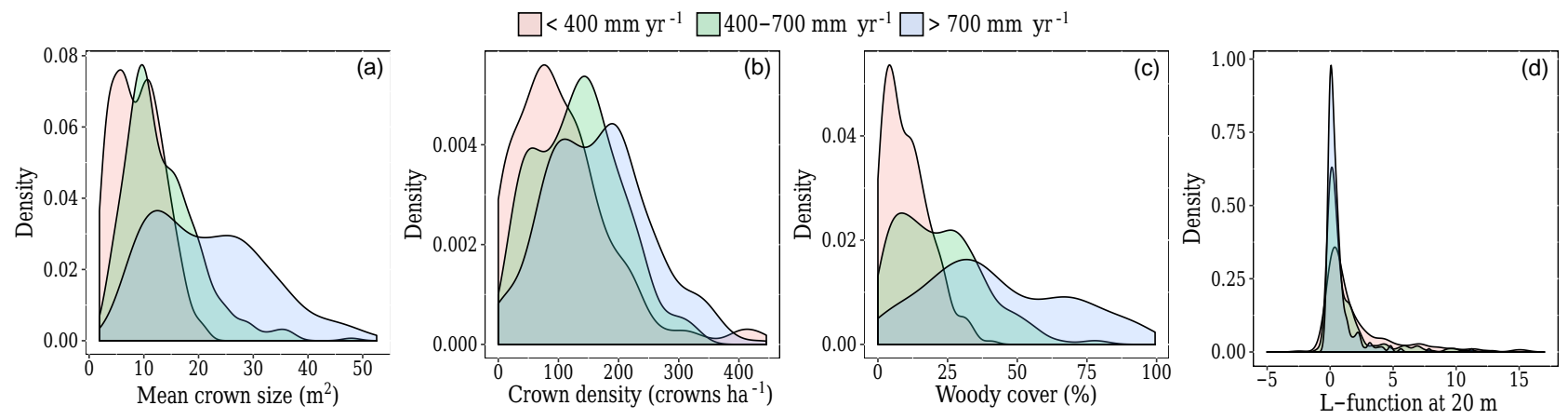

Figure 5. Frequency distributions of mean crown size, crown density, woody cover and aggregation calculated for different MAP ranges.
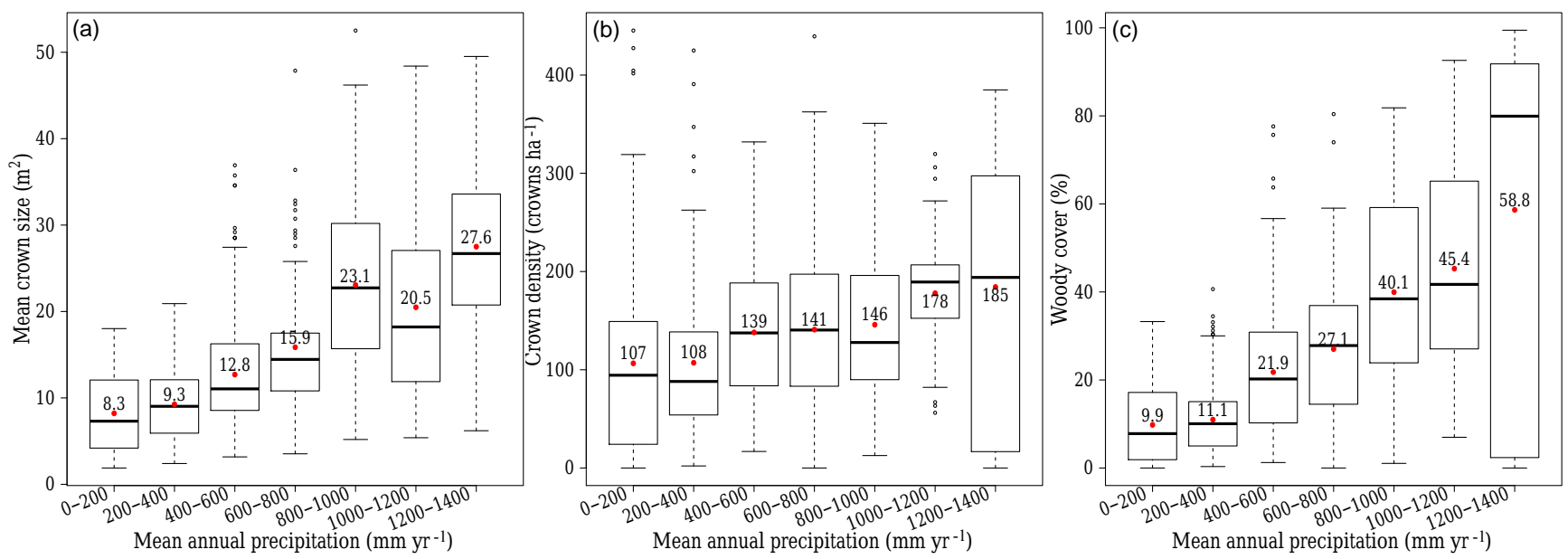

Figure 6. Boxplots of estimates of crown size, crown density, and woody cover along a rainfall gradient. Red points denote the means. Between the driest $\left(<200 \mathrm{~mm} \mathrm{yr}^{-1}\right)$ and wettest $\left(1200-1400 \mathrm{~mm} \mathrm{yr}^{-1}\right)$ categories, mean estimates of crown size, crown density, and woody cover increased by 233,73 , and $491 \%$ respectively.

Along the rainfall gradient from the driest $\left(<200 \mathrm{~mm} \mathrm{yr}^{-1}\right)$ to the wettest $\left(1200-1400 \mathrm{~mm} \mathrm{yr}^{-1}\right.$ ) end, mean estimates of crown size, crown density, and woody cover increased by 233,73 , and $491 \%$ respectively. The BRT models for woody cover and mean crown size had high cross-validated $R^{2}(0.73$ and 0.68), and the same environmental factors that control woody cover also had a large influence over crown sizes (Table 1). In both cases, MAP had the largest relative influence followed by rain seasonality. While MAP had a clear positive influence on both woody cover and crown sizes, it was more difficult to interpret the influence of rain seasonality (Fig. 7). Woody cover had a weak unimodal response to sand content, which was driven by the relationship between crown size and sand content (Fig. 7). Fire frequency resulted in weak negative responses on all woody properties.

\subsection{Woody plant aggregation}

Our estimates of aggregation were based on the $L$ statistic (at $20 \mathrm{~m}$ ) minus the distance, meaning positive values signal aggregated woody populations and negative values indi-
Table 1. Relative influence of each environmental variable and the cross-validated $R^{2}$ from the BRT models when modeling woody cover, crown density, and mean crown size.

\begin{tabular}{lrrr}
\hline Variables & $\begin{array}{r}\text { Mean crown } \\
\text { Size }\end{array}$ & $\begin{array}{r}\text { Crown } \\
\text { density }\end{array}$ & $\begin{array}{r}\text { Woody } \\
\text { cover }\end{array}$ \\
\hline MAP & $45 \%$ & $33 \%$ & $47 \%$ \\
Rain seasonality & $21 \%$ & $37 \%$ & $23 \%$ \\
Sand content & $17 \%$ & $13 \%$ & $10 \%$ \\
Slope & $11 \%$ & $13 \%$ & $10 \%$ \\
Fire frequency & $6 \%$ & $4 \%$ & $11 \%$ \\
\hline Cross-validated $R^{2}$ & 0.68 & 0.49 & 0.73 \\
\hline
\end{tabular}

cate dispersed populations (Fig. 8). The large majority (82\%) of sites had positive values, indicating a rarity of dispersed woody populations in African savannas. There was little difference in the results for aggregation when sites with periodic patterns were included or not (Table 2). Higher levels of aggregation were generally associated with high season- 


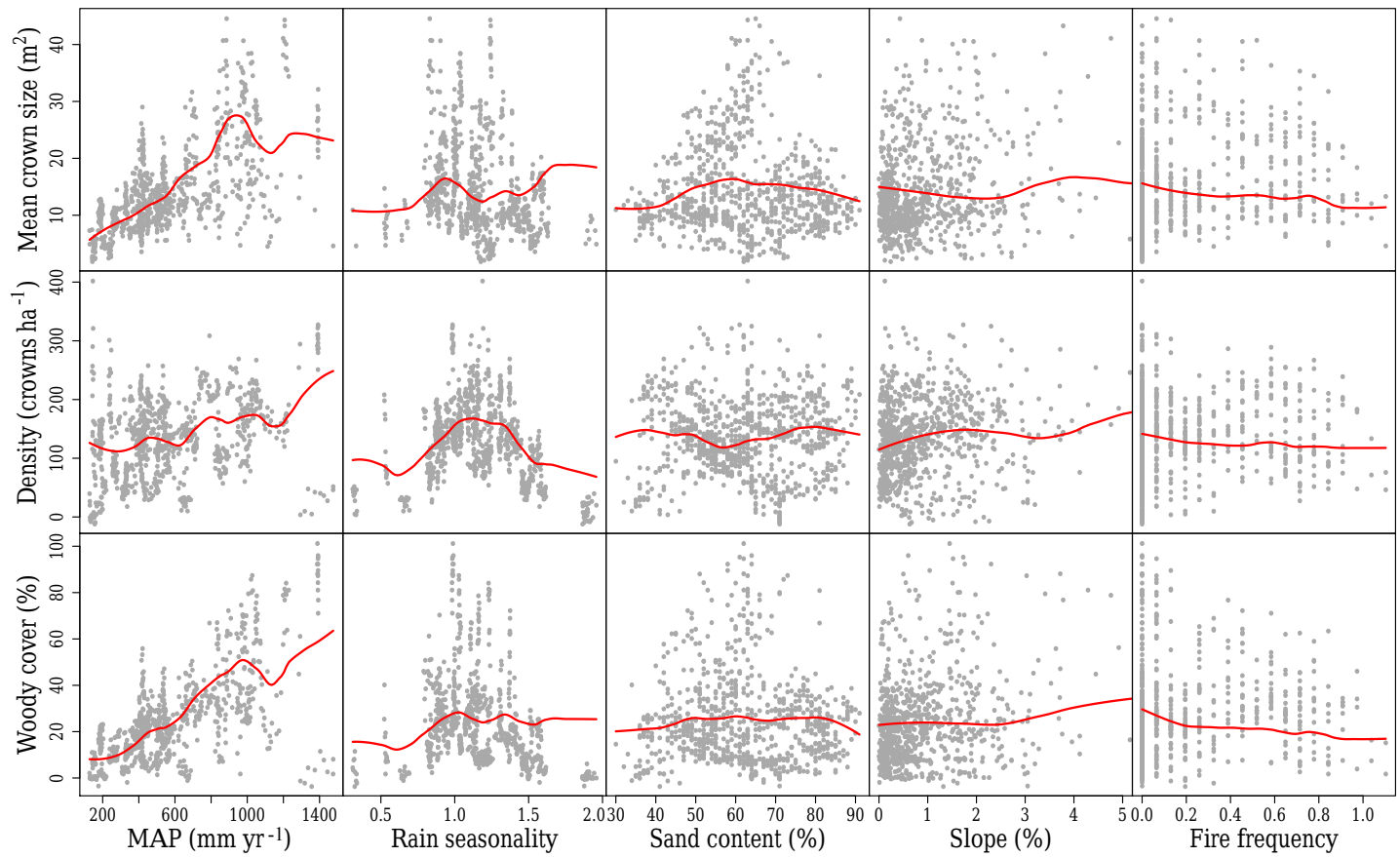

Figure 7. Modeled BRT responses ("partial dependencies") of woody canopy properties to each environmental variable when accounting for the average effect of the other four variables. The red lines are smoothed representations of the responses, with fitted values (model predictions based on the original data) for each of the 876 sites shown as grey dots. The $x$ axis for the slope predictor was truncated at $5 \%$ to highlight the response in the bulk of the data.

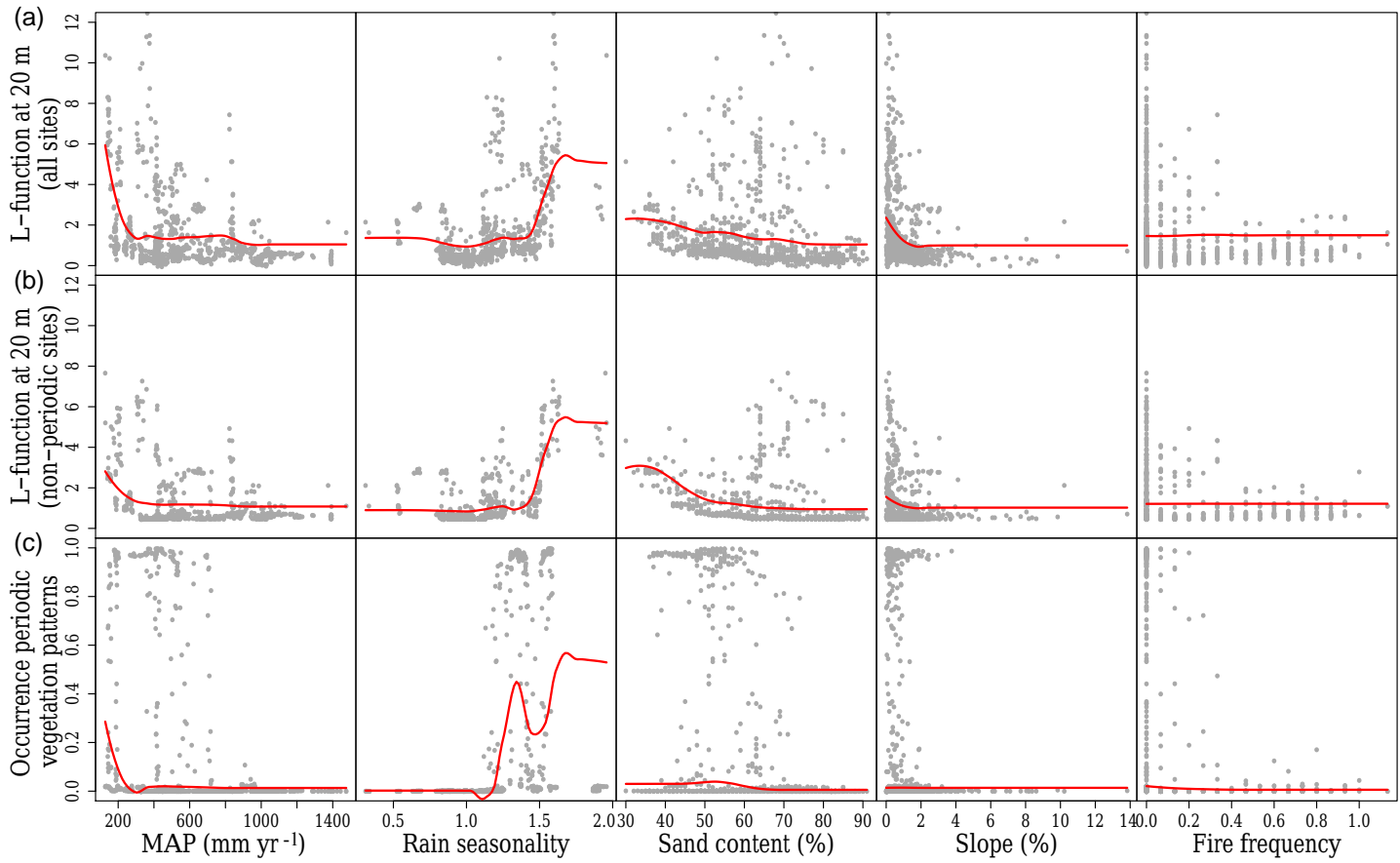

Figure 8. Modeled BRT responses ("partial dependencies") for predictions of under what conditions PVPs occur (top), and woody aggregation ( $L$-statistic at $20 \mathrm{~m}$ ) for all sites not categorized as having periodic patterns (bottom). The response for each environmental variable accounts for the average effect of the other four variables. The red lines are smoothed representations of the responses overlaying the fitted values (model predictions based on the original data; grey dots). 
Table 2. Relative influence of each environmental variable and the cross-validated $R^{2}$ from the BRT models when modeling woody aggregation ( $L$ function at $20 \mathrm{~m}$ ) and occurrence of PVPs. In the latter model, all sites with PVPs were given the value 1 and the rest the value 0 .

\begin{tabular}{lrrr}
\hline Variables & $\begin{array}{r}\text { Aggregation } \\
\text { (all sites) }\end{array}$ & $\begin{array}{r}\text { Aggregation } \\
\text { (non-periodic } \\
\text { sites) }\end{array}$ & $\begin{array}{r}\text { Occurrence } \\
\text { PVPs }\end{array}$ \\
\hline MAP & $28 \%$ & $16 \%$ & $20 \%$ \\
Rain seasonality & $44 \%$ & $51 \%$ & $46 \%$ \\
Topsoil sand & $14 \%$ & $16 \%$ & $21 \%$ \\
Slope & $14 \%$ & $17 \%$ & $1 \%$ \\
Fire frequency & $1 \%$ & $0 \%$ & $10 \%$ \\
\hline Cross-validated $R^{2}$ & 0.31 & 0.29 & 0.83 \\
\hline
\end{tabular}

ality, low MAP, fine-textured soils, and relatively flat terrain. These factors were also influential in determining the areas where periodic vegetation patterns occur. In fact, periodic patterns were absent in areas with MAP above $750 \mathrm{~mm}$, rain seasonality below 1.1 , a sand content above $75 \%$, and slopes steeper than $3.8 \%$.

Additional insight was drawn from analyzing aggregation along distances, with the data categorized into PVPs and subdivisions based on MAP and soil texture (Fig. 9). All categories were dispersed at short distances because each crown takes up space and there is bound to be a short distance between the center points of adjacent plants. Sites with PVPs had the highest levels of aggregation reaching a maximum at around $25 \mathrm{~m}$ (Fig. 9). The combination with wetter climes $(\geq 600 \mathrm{~mm}$ MAP) on coarse-textured soils $(\geq 60 \%$ sand) featured lower levels of aggregation than the other categories.

\section{Discussion}

\subsection{Dividing woody cover into density and crown size components}

Numerous authors have investigated how woody canopy cover varies across African savannas in response to variation in environmental variables (Good and Caylor, 2011; Sankaran et al., 2005; Staver et al., 2011). Given that tropical savannas cover about an eighth of Earth's land surface (Scholes and Archer, 1997) and contributes heavily to the global carbon cycle (Poulter et al., 2014), it is important to understand the makeup of these variations in terms of crown sizes and tree densities. By separating woody cover into mean crown size and density, we were able to analyze whether they respond differently to environmental factors and how they combine to drive landscape-scale woody cover across the continent. Our results suggest that crown sizes respond more strongly to rainfall than crown density (Fig. 6). This indicates that the commonly observed relationship of

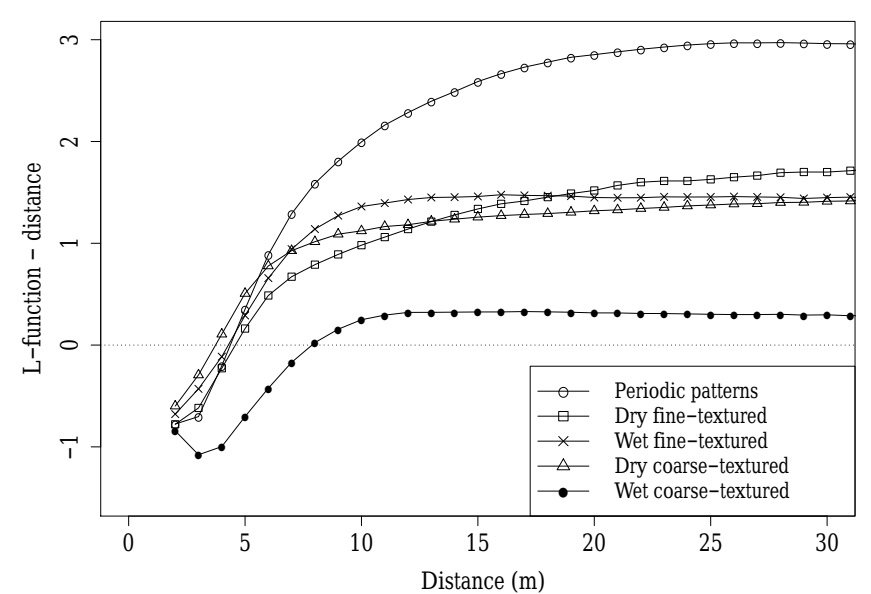

Figure 9. Level of aggregation among tree crowns calculated using Ripley's $K$ transformed to Besag's $L$ function. The figure shows the mean values of five categories: sites with periodic vegetation patterns, and four subdivisions based on mean annual precipitation and soil texture. Sites classified as having periodic patterns were not included in the latter subdivisions. Sites with MAP below $600 \mathrm{~mm}$ were categorized as dry, whereas sites with a sand content below $60 \%$ were categorized as fine-textured.

increasing woody cover with MAP in African savannas (e.g., Sankaran et al., 2005) is more a result of increasing size of trees than increasing tree density, at least in savannas with MAP $<700 \mathrm{~mm}$. We also found a unimodal relationship between crown sizes and soil texture that was not present in the results for crown density (Fig. 7). Soil properties have a considerable effect on the water cycle and a few studies have noticed that woody growth is suppressed on clayey soils in drylands (Lane et al., 1998; Sankaran et al., 2005; Williams et al., 1996). Recently, Fensham et al. (2015) showed that the effect is likely due to the higher wilting point on clays, which limits the soil moisture available for plants to extract. A combination of low rainfall and fine-textured soils can lead to very low soil water potentials and impact the vegetation in a way reminiscent of even drier conditions. In our results, the relationship appears unimodal with suppression on both the clayey and the sandiest end. Woody growth is then controlled by available soil moisture, which can be limited by either a high wilting point on clayey soils or low field capacity on sandy soils. Our results suggest these constraints affect the size of woody plants and not their abundance. Crown density was most strongly influenced by rainfall seasonality and appeared to have a unimodal response function (Fig. 7). The sites with very low rainfall seasonality $(<0.8)$ were all situated in the western part of East Africa (Serengeti, Masai Mara, and northern Uganda) in a region with bimodal rainfall distributions and far lower seasonality that further east. Many of these sites had low woody densities and cover but likely for other reasons than rainfall seasonality. Elephant densities are thought to be a key driver of woody cover in the Mara- 
Serengeti ecosystem (Morrison et al., 2016). Browsing, especially by elephants, has a great impact on woody structure (Sankaran et al., 2013) and is a key factor we did not capture in this analysis. If we focus on sites with rainfall seasonality above 0.8 , there is a more linear relationship with lower crown density and cover in areas with high rainfall seasonality which could be associated with the long periods of high water stress in more seasonal systems. Lehmann et al. (2014) found that high rainfall seasonality can constrain canopy closure and is an important predictor for the presence of savanna. Overall, the estimated woody properties were more strongly influenced by rainfall amounts and seasonality than by soil, slope, and fire. Fire frequency had a weak negative association with both woody cover, crown sizes, and densities. Fire has, however, an interactive relationship with vegetation structure (Archibald et al., 2009) and this analysis cannot separate the effect of fire on vegetation from impacts of vegetation structure on the fire regime.

\subsection{Woody plant aggregation and the occurrence of periodic vegetation patterns}

In accordance with previous research (Deblauwe et al., 2008), we found that the formation of highly aggregated PVPs is associated with specific environmental conditions. Periodic patterns are most likely to occur in areas with high rainfall seasonality low mean annual rainfall, fine-textured soils, and flat or gently sloping terrain (Fig. 8). These are factors that influence ecohydrological processes such as the propensity to form overland flows during rainfall events (Valentin et al., 1999). The results are in agreement with a global study on the biogeography of PVPs by Deblauwe et al. (2008), who found similar effects in regions with strong seasonal variation in temperature and more constant rainfall (Australia and Mexico) and in regions with distinct rainfall seasonality but more constant temperatures (Africa). Our analysis further shows that the same factors that contribute to PVP emergence are associated with higher levels of aggregation among woody plants elsewhere in African savannas. PVPs thus appear under conditions that naturally favor local facilitation and patchiness. However, the vegetation at many sites with these conditions does not exhibit highly organized periodic patterns, which could be related to soil properties other than texture. The dominant process in the formation of PVPs is a significant overland flow from bare to vegetated patches which requires near impervious soils. This property is typically associated with shallow soil depths, physical crusts, or hardpans (Leprun, 1999; McDonald et al., 2009), and is not strongly dependent on soil texture.

Previous studies have linked local aggregation and patchiness in savannas to fire frequency (Veldhuis et al., 2016b), seed dispersal (Pueyo et al., 2008), runoff-erosion processes (Ludwig et al., 2005), and short-range facilitation through modified microclimate close to nurse plants (Holmgren and Scheffer, 2010). With increasing abiotic stress, we expect stronger tree-tree facilitation in accordance with the stress gradient hypothesis (He et al., 2013). In our analysis, the most influential predictor for modeling aggregation was rainfall seasonality (Table 2), a factor that could influence plant dynamics in more than one way. The pronounced dry season associated with highly seasonal systems exerts a strong abiotic pressure, especially on juvenile trees with less developed root systems. Juvenile survival through the dry season is likely higher in the shelter of nearby trees. Over time, a bias in survival rates may lead to higher aggregation among adult trees. Once the wet season arrives, it often comes in heavy downpours which can quickly saturate the top soil leading to overland flows. This leads to both redistribution of water resources to woody patches with higher infiltration rates, as well as redistribution of litter and soil resources (Ludwig et al., 2005). The more concentrated rains may also alleviate competition for water during the growing season leading to facilitation being the dominant force in highly seasonal drylands. There was also a clear relationship between finetextured soils and higher aggregation. Fine-textured soils increase runoff through lower infiltration rates, and may also amplify stress during the dry season through their higher wilting point. Sites with the combination of coarse-textured soils ( $\geq 60 \%$ sand) and wetter climes ( $\geq 600 \mathrm{~mm}$ MAP) stood out in the analysis by being far less aggregated (Fig. 9). This points to the interactive effects of these variables. We found no link between fire frequency and aggregation and a weak relationship with slope favoring aggregation on flat or gently sloping terrain. This relationship can also be explained in terms of overland flows. Steeper slopes tend to create drainage rills leading the water downhill which break up the local patch-interpatch redistribution of resources (Saco and Moreno-de las Heras, 2013).

\section{Conclusions}

Using high-spatial-resolution imagery, a flexible classification framework, and a crown delineation methodology, we estimated several key woody vegetation properties in African savannas and analyzed how these vary with local environmental conditions. We find that woody cover, crown sizes, and woody plant densities are more strongly influenced by rainfall amounts and seasonality than by soil texture, slope, and fire frequency. Of specific interest is that mean crown size responded more strongly to mean annual rainfall than plant densities, indicating that the commonly observed relationships between woody cover and rainfall (e.g., Sankaran et al., 2005) is more a result of increasing crown sizes than variation in crown density. Larger crown sizes were associated with mid-textured soils and appeared suppressed on both clays and very sandy soils. The level of aggregation among woody plants was most strongly related to rainfall seasonality, as was the occurrence of PVPs. Similar processes that influence patchiness in savannas also contribute to the for- 
mation of PVPs, with impermeable soil conditions being the possible difference between a patchy savanna landscape and highly organized periodic vegetation.
Data availability. The estimates of woody vegetation properties are available in the Supplement of this paper. 


\section{Appendix A: Validation of estimated woody vegetation properties using field data from Kenya}

This appendix describes a validation analysis of estimated mean crown size, crown density, and woody cover using field data collected in southern Kenya during September-October 2015. Plots were established in five protected areas: Tsavo West NP, Tsavo East NP, Amboseli NP, Ol Pejeta wildlife conservancy, and Il Ngwesi group ranch (Fig. A1). In total, we established 28 plots with at least four plots in each protected area. The size of plots varied with the density of trees and shrubs, ranging from 350 to $8000 \mathrm{~m}^{2}$ with a median at $1450 \mathrm{~m}^{2}(38 \times 38 \mathrm{~m})$. The positions of plot corners were determined with a GPS and the positions of trees and shrubs within each plot were measured with a laser rangefinder from the plot corners. Using measuring tape, we determined the diameter of crowns along the longest axis and on the perpendicular. From these two measurements, we later calculated crown sizes assuming elliptic crown shapes. We acquired the best available high-resolution imagery covering the sites from 2012 or later. In some cases, this resulted in imagery of lower quality (few green leaves on the trees) than the imagery used in the continental analysis.

Our analysis of detection ratios (Fig. A2) indicated a detection threshold of $\sim 2 \mathrm{~m}$ below which smaller trees and shrubs were not reliably detected, while most individuals with crown diameter $>3 \mathrm{~m}$ were detected. The detection ratios were likely negatively influenced by the sometimes low quality of the imagery and the time difference between image acquisition and field work (often 2-3 years).

When calculating the relationship between estimated and field-measured woody properties (Fig. A3), we excluded all field-measured trees and shrubs with a diameter less than the $2 \mathrm{~m}$ detection threshold. Estimates of the woody properties then fall relatively close to the one-to-one line. The four sites in Amboseli were dominated by large umbrella thorn acacias (Vachellia tortilis) with particularly large and spreadout crowns (Fig. A4). The spread-out architecture of these crowns make them appear as several distinct crowns from above, and the delineation algorithm did not identify them as single trees. The large majority of our sites in the continental analysis do not contain these types of trees, which are relatively rare across all of African savannas. Since they dominated all four sites in Amboseli, we determined that they were overrepresented in the field dataset and therefore chose to exclude the Amboseli sites when calculating $R^{2}$ for mean crown size and crown density. We also excluded one site in Ol Pejeta (OLP3) where the smaller trees lacked green leaves in the imagery and could not be detected.

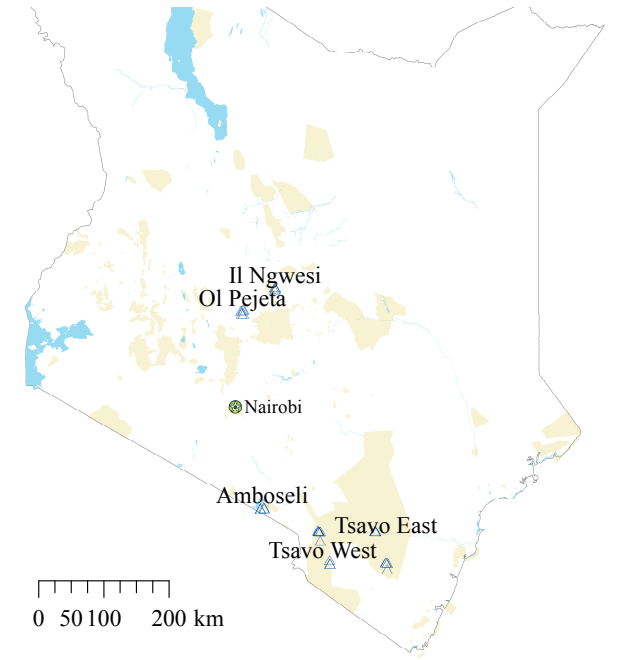

Figure A1. Map of the five protected areas in southern Kenya where field work was conducted. The positions of individual plots are marked with blue triangles.

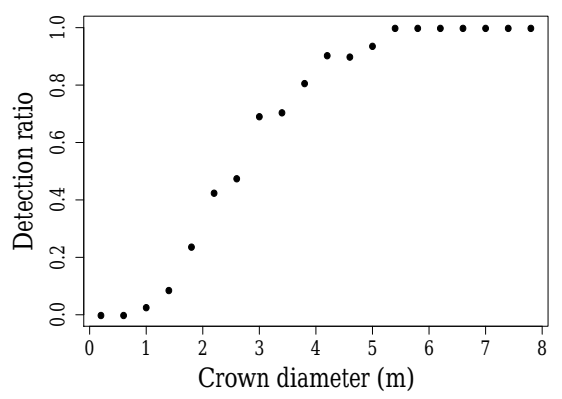

Figure A2. Detection ratios of woody plants in classified imagery at field work sites. The values were calculated as mean detection ratios for trees divided into bins of width $40 \mathrm{~cm}$. 

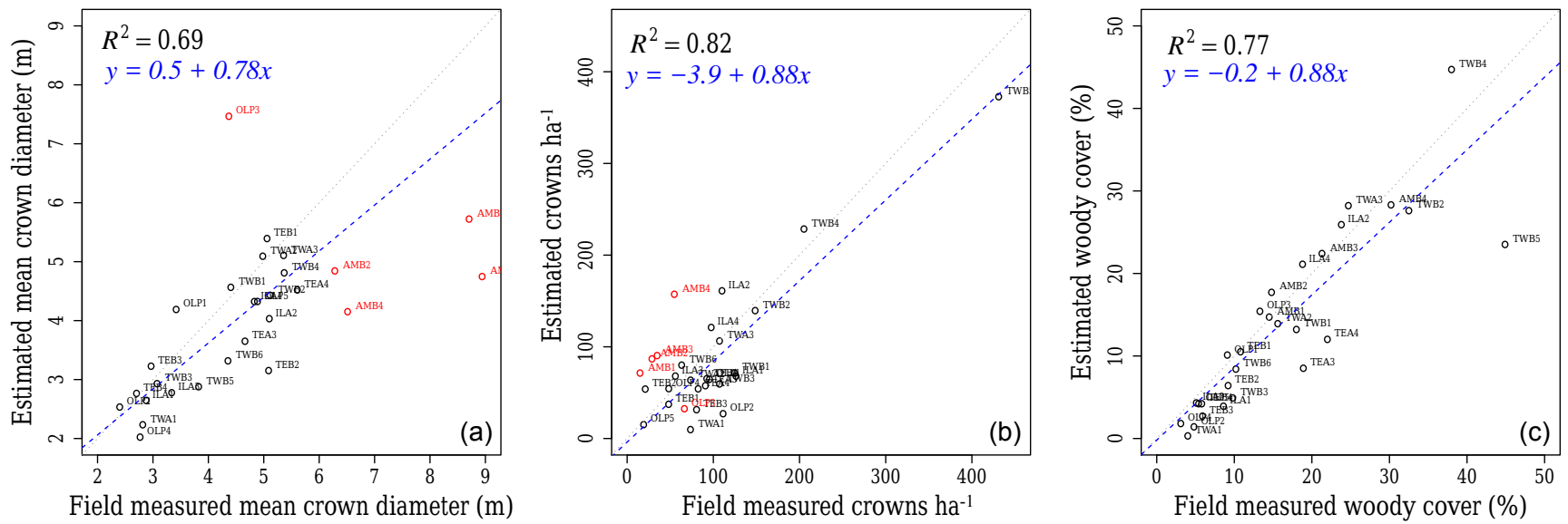

Figure A3. Validation of estimated mean crown size, crown density, and woody cover. The Amboseli sites and one site in Ol Pejeta were excluded when calculating $R^{2}$ for mean crown size and crown density. These sites are shown in red.
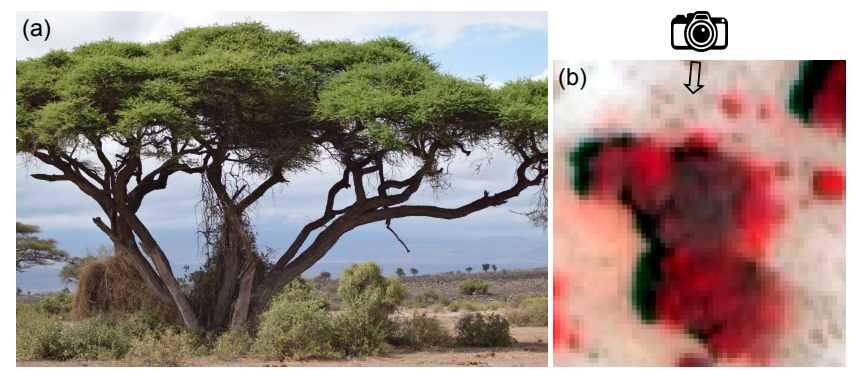

Figure A4. Vachellia tortilis at a field work site in Amboseli NP, Kenya. Panel (a) shows two trees with overlapping crowns, with the second being further back on the left. Panel (b) shows the same trees in false-color satellite imagery. The spread-out architecture of the canopy makes them appear as several distinct crowns. The camera symbol roughly indicates the position from which the ground photo was taken. 


\section{The Supplement related to this article is available online at https://doi.org/10.5194/bg-14-3239-2017-supplement.}

Competing interests. The authors declare that they have no conflict of interest.

Acknowledgements. The satellite data were provided through a NASA agreement and under NextView license. We thank Jamie Nickeson, Njoki Kahiu, Sujan Parajuli, and Dinesh Shrestha for assistance with data retrieval, field work, and image classification. We also thank the Kenya Wildlife Service (KWS), Ol Pejeta Conservancy, and Ilngwesi group ranch for access to field sites in Kenya. The project was funded by the National Science Foundation (Coupled Natural-Human Systems Program) and the NASA Terrestrial Ecology Program. C. R. Axelsson was also supported by a graduate research fellowship through the Geospatial Sciences Center of Excellence at South Dakota State University.

Edited by: Kirsten Thonicke

Reviewed by: Penny Mograbi and Sytze de Bruin

\section{References}

Archibald, S., Roy, D. P., van Wilgen, B. W., and Scholes, R. J.: What limits fire? An examination of drivers of burnt area in southern Africa, Glob. Change Biol., 15, 613-630, 2009.

Barbier, N., Bellot, J., Couteron, P., Parsons, A. J., and Mueller, E. N.: Short-Range Ecogeomorphic Processes in Dryland Systems Patterns of Land Degradation in Drylands, Springer, Dordrecht, the Netherlands, 85-101, https://doi.org/10.1007/978-94007-5727-1_4, 2014.

Besag, J.: Comments on Ripley's paper, J. Roy. Stat. Soc. B, 39, 193-195, 1977.

Bond, W. J.: What limits trees in $\mathrm{C} 4$ grasslands and savannas?, Annu. Rev. Ecol. Evol. S., 39, 641-659, 2008.

Bunting, P. and Lucas, R.: The delineation of tree crowns in Australian mixed species forests using hyperspectral Compact Airborne Spectrographic Imager (CASI) data, Remote Sens. Environ., 101, 230-248, 2006.

Chesson, P., Gebauer, R. L., Schwinning, S., Huntly, N., Wiegand, K., Ernest, M. S., Sher, A., Novoplansky, A., and Weltzin, J. F.: Resource pulses, species interactions, and diversity maintenance in arid and semi-arid environments, Oecologia, 141, 236-253, 2004.

Culvenor, D. S.: TIDA: an algorithm for the delineation of tree crowns in high spatial resolution remotely sensed imagery, Comput. Geosci., 28, 33-44, 2002.

Deblauwe, V., Barbier, N., Couteron, P., Lejeune, O., and Bogaert, J.: The global biogeography of semi-arid periodic vegetation patterns, Global Ecol. Biogeogr., 17, 715-723, 2008.

Dohn, J., Augustine, D. J., Hanan, N. P., Ratnam, J., and Sankaran, M.: Spatial vegetation patterns and neighborhood competition among woody plants in an East African savanna, Ecology, 98, 478-488, 2017.
Elith, J., Leathwick, J. R., and Hastie, T.: A working guide to boosted regression trees, J. Anim. Ecol., 77, 802-813, 2008.

Ellis, E. C. and Ramankutty, N.: Putting people in the map: anthropogenic biomes of the world, Front. Ecol. Environ., 6, 439-447, 2008.

Farr, T. G., Rosen, P. A., Caro, E., Crippen, R., Duren, R., Hensley, S., Kobrick, M., Paller, M., Rodriguez, E., and Roth, L.: The shuttle radar topography mission, Rev. Geophys., 45, RG2004, https://doi.org/10.1029/2005RG000183, 2007.

Fensham, R. J., Butler, D. W., and Foley, J.: How does clay constrain woody biomass in drylands?, Global Ecol. Biogeogr., 24, 950958, 2015.

Gan, T. Y., Ito, M., Hülsmann, S., Qin, X., Lu, X., Liong, S., Rutschman, P., Disse, M., and Koivusalo, H.: Possible climate change/variability and human impacts, vulnerability of droughtprone regions, water resources and capacity building for Africa, Hydrolog. Sci. J., 61, 1209-1226, 2016.

Giglio, L., Loboda, T., Roy, D. P., Quayle, B., and Justice, C. O.: An active-fire based burned area mapping algorithm for the MODIS sensor, Remote Sens. Environ., 113, 408-420, 2009.

Gómez-Aparicio, L., Zamora, R., Castro, J., and Hódar, J. A.: Facilitation of tree saplings by nurse plants: Microhabitat amelioration or protection against herbivores?, J. Veg. Sci., 19, 161-172, 2008.

Good, S. P. and Caylor, K. K.: Climatological determinants of woody cover in Africa, P. Natl. Acad. Sci. USA, 108, 4902-4907, 2011.

He, Q., Bertness, M. D., and Altieri, A. H.: Global shifts towards positive species interactions with increasing environmental stress, Ecol. Lett., 16, 695-706, 2013.

Hengl, T., Heuvelink, G. B., Kempen, B., Leenaars, J. G., Walsh, M. G., Shepherd, K. D., Sila, A., MacMillan, R. A., de Jesus, J. M., and Tamene, L.: Mapping soil properties of Africa at $250 \mathrm{~m}$ resolution: Random forests significantly improve current predictions, PloS one, 10, e0125814, https://doi.org/10.1371/journal.pone.0125814, 2015.

Holmgren, M. and Scheffer, M.: Strong facilitation in mild environments: the stress gradient hypothesis revisited, J. Ecol., 98 1269-1275, 2010.

Huffman, G. J., Bolvin, D. T., Nelkin, E. J., Wolff, D. B., Adler, R. F., Gu, G., Hong, Y., Bowman, K. P., and Stocker, E. F. The TRMM multisatellite precipitation analysis (TMPA): Quasiglobal, multiyear, combined-sensor precipitation estimates at fine scales, J. Hydrometeorol., 8, 38-55, 2007.

Karlson, M., Reese, H., and Ostwald, M.: Tree crown mapping in managed woodlands (parklands) of semi-arid West Africa using Worldview-2 imagery and geographic object based image analysis, Sensors, 14, 22643-22669, 2014.

Lane, D. R., Coffin, D. P., and Lauenroth, W. K.: Effects of soil texture and precipitation on above-ground net primary productivity and vegetation structure across the Central Grassland region of the United States, J. Veg. Sci., 9, 239-250, 1998.

Lehmann, C. E. R., Anderson, T. M., Sankaran, M., Higgins, S. I., Archibald, S., Hoffmann, W. A., Hanan, N. P., Williams, R. J., Fensham, R. J., Felfili, J., Hutley, L. B., Ratnam, J., San Jose, J., Montes, R., Franklin, D., Russell-Smith, J., Ryan, C. M., Durigan, G., Hiernaux, P., Haidar, R., Bowman, D. M. J. S., and Bond, W. J.: Savanna Vegetation-Fire-Climate Re- 
lationships Differ Among Continents, Science, 343, 548-552, https://doi.org/10.1126/science.1247355, 2014.

Leprun, J. C.: The influences of ecological factors on tiger bush and dotted bush patterns along a gradient from Mali to northern Burkina Faso, Catena, 37, 25-44, 1999.

Ludwig, J. A., Wilcox, B. P., Breshears, D. D., Tongway, D. J., and Imeson, A. C.: Vegetation patches and runoff-erosion as interacting ecohydrological processes in semiarid landscapes, Ecology, 86, 288-297, 2005.

McDonald, A. K., Kinucan, R. J., and Loomis, L. E.: Ecohydrological interactions within banded vegetation in the northeastern Chihuahuan Desert, USA, Ecohydrology, 2, 66-71, 2009.

Morrison, T. A., Holdo, R. M., and Anderson, T. M.: Elephant damage, not fire or rainfall, explains mortality of overstorey trees in Serengeti, J. Ecol., 104, 409-418, 2016.

Pillay, T. and Ward, D.: Competitive effect and response of savanna tree seedlings: comparison of survival, growth and associated functional traits, J. Veg. Sci., 25, 226-234, 2014.

Pouliot, D. and King, D.: Approaches for optimal automated individual tree crown detection in regenerating coniferous forests, Can. J. Remote Sens., 31, 255-267, 2005.

Poulter, B., Frank, D., Ciais, P., Myneni, R. B., Andela, N., Bi, J., Broquet, G., Canadell, J. G., Chevallier, F., and Liu, Y. Y.: Contribution of semi-arid ecosystems to interannual variability of the global carbon cycle, Nature, 509, 600-603, 2014.

Pueyo, Y., Kefi, S., Alados, C., and Rietkerk, M.: Dispersal strategies and spatial organization of vegetation in arid ecosystems, Oikos, 117, 1522-1532, 2008.

Rasmussen, M. O., Göttsche, F.-M., Diop, D., Mbow, C., Olesen, F.-S., Fensholt, R., and Sandholt, I.: Tree survey and allometric models for tiger bush in northern Senegal and comparison with tree parameters derived from high resolution satellite data, Int. J. Appl. Earth Obs., 13, 517-527, 2011.

Rietkerk, M. and van de Koppel, J.: Regular pattern formation in real ecosystems, Trends Ecol. Evol., 23, 169-175, 2008.

Riginos, C. and Grace, J. B.: Savanna tree density, herbivores, and the herbaceous community: bottom-up vs. top-down effects, Ecology, 89, 2228-2238, 2008.

Ripley, B. D.: Modelling spatial patterns, J. Roy. Stat. Soc. B, 39, 172-212, 1977.

Saco, P. M. and Moreno-de las Heras, M.: Ecogeomorphic coevolution of semiarid hillslopes: Emergence of banded and striped vegetation patterns through interaction of biotic and abiotic processes, Water Resour. Res., 49, 115-126, 2013.
Sankaran, M., Hanan, N. P., Scholes, R. J., Ratnam, J., Augustine, D. J., Cade, B. S., Gignoux, J., Higgins, S. I., Le Roux, X., and Ludwig, F.: Determinants of woody cover in African savannas, Nature, 438, 846-849, 2005.

Sankaran, M., Ratnam, J., and Hanan, N.: Woody cover in African savannas: the role of resources, fire and herbivory, Global Ecol. Biogeogr., 17, 236-245, 2008.

Sankaran, M., Augustine, D. J., and Ratnam, J.: Native ungulates of diverse body sizes collectively regulate long-term woody plant demography and structure of a semi-arid savanna, J. Ecol., 101, 1389-1399, 2013.

Scanlon, T. M., Caylor, K. K., Levin, S. A., and Rodriguez-Iturbe, I.: Positive feedbacks promote power-law clustering of Kalahari vegetation, Nature, 449, 209-212, 2007.

Scholes, R. and Archer, S.: Tree-grass interactions in savannas, Annu. Rev. Ecol. Syst., 28, 517-544, 1997.

Shackleton, C. and Scholes, R.: Above ground woody community attributes, biomass and carbon stocks along a rainfall gradient in the savannas of the central lowveld, South Africa, S. Afr. J. Bot., 77, 184-192, 2011.

Staver, A. C., Archibald, S., and Levin, S.: Tree cover in subSaharan Africa: Rainfall and fire constrain forest and savanna as alternative stable states, Ecology, 92, 1063-1072, 2011.

Valentin, C., d'Herbès, J.-M., and Poesen, J.: Soil and water components of banded vegetation patterns, Catena, 37, 1-24, 1999.

Veldhuis, M. P., Hulshof, A., Fokkema, W., Berg, M. P., and Olff, H.: Understanding nutrient dynamics in an African savanna: local biotic interactions outweigh a major regional rainfall gradient, J. Ecol., 104, 913-923, https://doi.org/10.1111/13652745.12569, 2016a.

Veldhuis, M. P., Rozen-Rechels, D., Roux, E., Cromsigt, J. P., Berg, M. P., and Olff, H.: Determinants of patchiness of woody vegetation in an African savanna, J. Veg. Sci., 28, 93-104, https://doi.org/10.1111/jvs.12461, 2016b.

Williams, R., Duff, G., Bowman, D., and Cook, G.: Variation in the composition and structure of tropical savannas as a function of rainfall and soil texture along a large-scale climatic gradient in the Northern Territory, Australia, J. Biogeogr., 23, 747-756, 1996.

Xu, C., Holmgren, M., Van Nes, E. H., Maestre, F. T., Soliveres, S., Berdugo, M., Kéfi, S., Marquet, P. A., Abades, S., and Scheffer, M.: Can we infer plant facilitation from remote sensing? a test across global drylands, Ecol. Appl., 25, 1456-1462, 2015. 